\title{
Review
}

\section{Post-harvest processing of coffee: An overview}

\author{
Suryatapa Das ${ }^{1}$
}

${ }^{1}$ University of Calcutta, Department of Food and Nutrition, Maharani Kasiswari College, Kolkata, India

Contact authors: dassuryatapa@gmail.com

Received in October 19, 2021 and approved January 18, 2022

\section{ABSTRACT}

Coffee is known as one of the most popular beverages around the world. Coffee belongs to the botanical family Rubiaceae and genus coffea. The two most economically important species are $C$. arabica (arabica coffee) and C. canephora (robusta coffee).The health benefits of coffee are due to presence of many biologically active components such as caffeine, chlorogenic acid, nicotinic acid, quinolinic acid, trigonelline, tannic acid, and pyrogolic acid. The postharvest processing of coffee cherry involves dry or wet processing, grading, sorting, marketing, blending, and roasting. A series of physical and chemical changes occur during coffee roasting that are responsible for the development of pleasant aroma and flavour of coffee.

Key words: Arabica; Coffee cherry; Roasting; Robusta; Rubiacea.

\section{INTRODUCTION}

Coffee is one of the most popular beverages consumed widely around the world. Nearly 25 million farmers in 50 countries around the world depend on coffee as a significant part of their lives (Cague et al., 2009). The coffee belongs to botanical family Rubiaceae having about 500 genera and over 6000 species (Ukers, 1922). Coffee belongs to genus Coffea, which is the most economically important member of the Rubiaceae family (Murthy; Naidu, 2012) .Coffee is grown in tropical and subtropical regions of Central and South America, South East Asia, and Africa (Schenker, 2000). When harvested, the coffee fruits are called coffee cherries. Coffee cherries a re harvested every year when they are bright-red, glossy and firm. After removal of the outer hull, the seeds inside the cherries are commonly called "green coffee beans"(Ghosh; Venkatachalapath, 2014). Coffee pods are naturally grown i $n$ the shade of African forests, including the islands of Madagascar and Mauritius (the latter formerly known as one of the Mascarene Islands), and cultivated in tropical areas such as equatorial Africa, Java, Sumatra, and other islands of the Dutch East Indies, West Indies, India, Arabia, the islands of the Pacific, Mexico, and Central and South America (Davis et al., 2007; Ukers, 1922). The leading coffee producing countries in the world include Brazil, Vietnam, Colombia, Indonesia, Ethiopia, and India (Davis et al., 2006).

\section{COFFEE FRUIT AND STRUCTURE OF COFFEE BEAN}

O ver 90 species of coffee genus were described of which 25 species are extensively studied (Davis et al.,
2 007; Charrier; Berthaud, 1987). Of these 25 species, only two are of major economic importance: Coffea Arabica and coffea canaphora. The Arabica plant is a tetraploid species $(2 \mathrm{n}=4 \mathrm{x}=44)$ originated from natural hybridization between Coffea canephora and Coffea eugenioides, or ecotypes related to these two diploids $(2 \mathrm{n}=2 \mathrm{x}=22)$ species (Anthony, 2002; Charrier; Berthaud, 1987; Lashermes et al., 1999). Triploid h ybrids originated from crosses between $C$. arabica, and diploid species have been reported. They tend to be robust plants but almost completely sterile (Charrier; Berthaud, 1987). Coffea arabica trees are generally up to $6 \mathrm{~m}$ in height, grow well at high elevations and mild temperatures, and account for over $60 \%$ of the world's total coffee production.

Coffea canephora trees reach up to $10 \mathrm{~m}$ in height, grow at low elevations and warmer climates, and have higher resistance to diseases, inferior cup quality, and lower market value compared to Arabica trees. Their seeds account for less than $40 \%$ of the world's coffee production (Farah; Santos, 2015).

The most economical relevant varieties are $C$. arabica and C. canephora (Farah; Santos, 2015). The popular variety of canephora is as described C. robusta. It is a robust shrub or small tree growing up to 10 meters in height, but with a shallow root system. The fruits are rounded and matured in 11 months. The seeds are oval in shape and smaller than those of C. arabica Robusta coffee grown in West and Central Africa, throughout South-East Asia and to some extent in Brazil, where it known as Conillon.

The coffee fruit comprises (i) the skin (epicarp or exocarp), which is a monocellular layer covered with a waxy substance that protects the fruit; it is usually red, dark pink, 
or yellow; (ii) the pulp (mesocarp), which comprises a fleshy pulp and, when the fruit ripens, a slimy pectinaceous layer of mucilage adhering to parchment is found, known as pectin layer;(iii)the parchment or parch (endocarp), which is a thin, crumbly, paper-like polysaccharide covering; (iv) the silver skin, which is the seed coat underneath the endocarp and c o m p o sed of mainly polysaccharides, especially cellulose and hemicelluloses, in addition to monosaccharides, proteins, polyphenols, and other minor compounds; and (v) two elliptical o $\mathrm{r}$ e g g-shaped seeds containing endosperm and embryos (Murthy; Naidu, 2012; FAO, 2005; CAC; FAO/WHO, 2009) (Figure 1 and Figure 2).

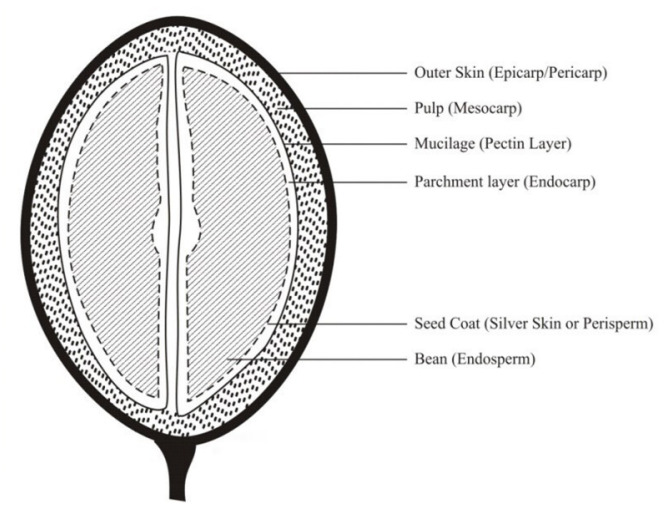

Figure 1: Inner structure of coffee cherries.

Each cherry consists of two coffee seeds or beans of which only one is assumed to be a rounder shape and it is known as pea-berry (Ghosh; Venkatachalapath, 2014).

\section{CHEMICAL COMPOSITION AND NUTRITIVE VALUE OF COFFEE}

Green coffee beans are primarily composed of insoluble polysaccharides such as cellulose and hemicellulose (about 50 percent). They also contain soluble carbohydrates, such as monosaccharaides (fructose, glucose, galactose, and arabinose), oligosaccharides (sucrose, raffinose, and stachyose), and polymers of galactose, mannose, arabinose, and glucose. Soluble carbohydrates help in binding of aroma, stabilization of foam, sedimentation, and increasing viscosity of the extract. In addition, non-volatile aliphatic acids (citric, malic and quinic acids) and volatile acids (such as acetic, propanoic, butanoic, isovaleric, hexanoic acids) are also present. Oils and waxes account for 8 to $18 \%$ of the dry mass, together with proteins and free amino acids (9-12\% $\mathrm{w} / \mathrm{w}$ ) and minerals $(3-5 \% \mathrm{w} / \mathrm{w})$ in coffee beans (Ghosh; Venkatachalapath, 2014). The chemical composition of green Arabica and Robusta beans are shown in Table 1. (Ghosh; Venkatachalapath, 2014).
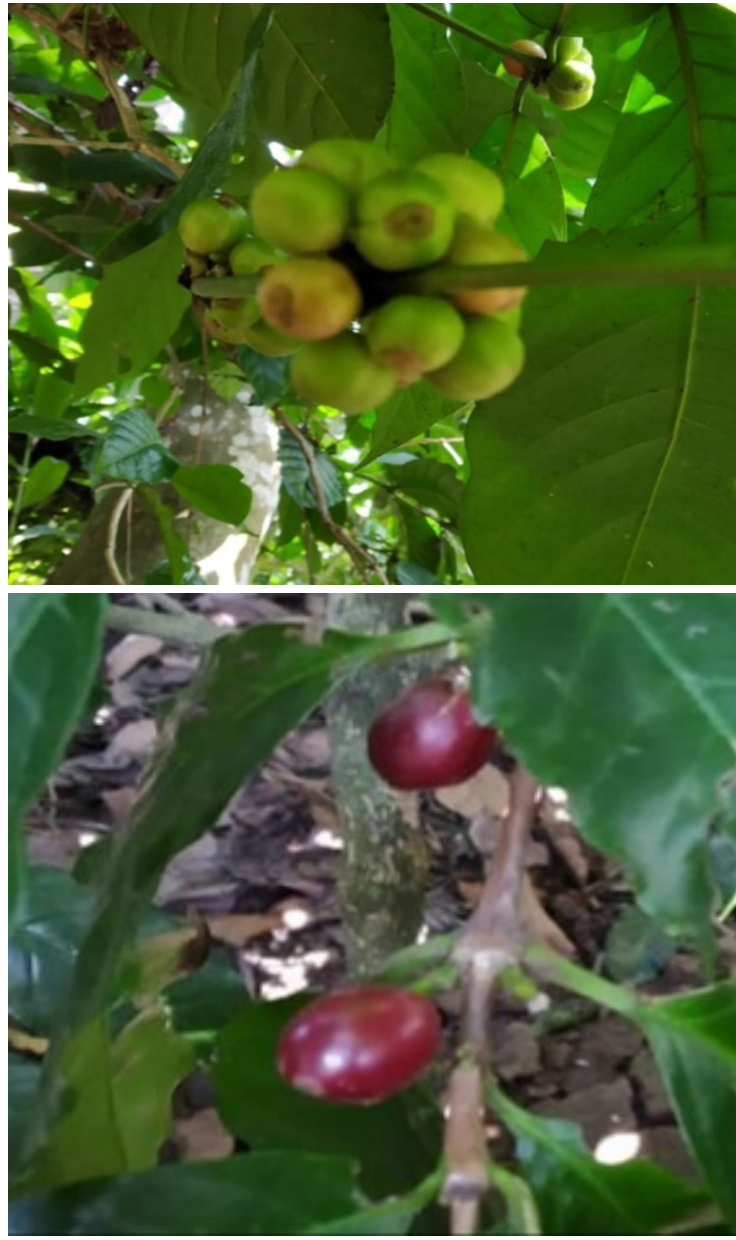

Figure 2: Coffee Cherries (A) Unripe and (B) Ripe.

Table 1: Chemical composition of green coffee.

\begin{tabular}{cccc}
\hline \multirow{2}{*}{$\begin{array}{c}\text { Sl. } \\
\text { No. }\end{array}$} & Composition & $\begin{array}{c}\text { Arabica } \\
\text { coffee }\end{array}$ & $\begin{array}{c}\text { Robusta } \\
\text { coffee }\end{array}$ \\
\cline { 3 - 4 } & & \multicolumn{2}{c}{$(\mathrm{g} / 100 \mathrm{~g})$} \\
\hline 1 & Polysaccharides & 49.8 & 54.4 \\
2 & Sucrose & 8.0 & 4.0 \\
3 & Reducing Sugars & 0.1 & 0.4 \\
4 & Other sugars & 1.0 & 2.0 \\
5 & Lipids & 16.2 & 10.0 \\
6 & Proteins & 9.8 & 9.5 \\
7 & Amino acids & 0.5 & 0.8 \\
8 & Aliphatic acids & 1.1 & 1.2 \\
9 & Quinic acids & 0.4 & 0.4 \\
10 & Chlorogenic acids & 6.5 & 10 \\
11 & Caffeine & 1.2 & 2.2 \\
12 & Trigonelline & 1.0 & 0.7 \\
13 & Minerals(oxide ash) & 4.2 & 4.4 \\
14 & Volatile aroma & Traces & Traces \\
15 & Water & 8 to 12 & 8 to 12 \\
\hline
\end{tabular}


There are many compounds in coffee that are often thought to have implications upon human health. These i nclude caffeine, micronutrients and chlorogenic acid. The coffee beverage is rich in biologically active substances such a s nicotinic acid, quinolinic acid, trigonelline, tannic acid, pyrogallic acid and caffeine (Minamisawa et al., 2004)

\section{PROCESSING OF GREEN COFFEE}

\subsection{Harvesting}

Harvesting is an important step to yield good-quality coffee. As coffee fruits on the same plant usually do not reach ripeness at the same time, harvesting usually begins when the majority of fruits are ripe. This process can occur manually or mechanically. Manual harvesting may be performed by picking cherries one by one or by stripping the twigs and collecting all fruits, including the ripe, immature, and overripe o nes. Mechanical harvesting is done either by shaking the trees or by stripping the branches with an apparatus similar to a flexible comb. Compared to other methods, picking can be time-consuming and expensive in places where the required workforce is not readily available. However, it tends to produce better-quality coffee beans compared to the other methods. $\mathrm{T}$ he other methods may yield many extrinsic and intrinsic defects derived from fruits at different degrees of maturation as well as fermented or oxidized fruits (Farah, 2009; Farah et al., 2006; Toci; Farah, 2008).

\subsection{Processing}

After harvesting, the fruits required to undergo primary processing to separate the seeds from the rest of the fruit and then sorting them according to the number and types of defects, size and other parameters to assist in classifying and grading the coffee lots The most common methods to separate the seeds from the outer parts of the fruit are known as dry and wet methods (Figure 3).

\subsubsection{Dry processing}

Dry processing is simpler of the two methods and is a popular method in Brazil to process Robusta coffee and in Sri Lanka to process Arabica coffee. In general, in the original dry method harvested seeds are parched by exposure to the sun in large yards (which may take from 1 to 2 weeks) and/or by air dryers until the moisture content reduce up to 10 to $12 \%$ to prevent bacterial and fungal growth. Racking is one of the most important step of processing in dry method. The greater number of racking gives a uniform and better quality product (Ghosh; Venkatachalapath, 2014).

In general, in the original dry method harvested seeds are parched by exposure to the sun in large yards (which may take from 1 to 2 weeks) and/or by air dryers until the moisture content reduce up to 10 to $12 \%$ to prevent bacterial and fungal growth. Racking is one of the most important processing in dry method. The greater number of racking gives a uniform and better quality product (Ghosh,Venkatachalapath, 2014).

The dried cherry is then hulled to remove the pericarp by hand using a pestle and mortar or in a mechanical huller. The mechanical huller usually consists of a steel screw, the pitch of which increases as it approaches the outlet so removing the pericarp. The hulled coffee is cleaned by winnowing. Defective beans are also removed. Sorting takes place both in the producing and manufacturing countries to achieve high quality coffee beans, and is carried out by either mechanical or optical means. In the mechanical method, defective beans are hand-picked and fed into air classifiers (catadors) where they are passed through an adjustable rising current of air. The product obtained after the dry primary process is "natural" green coffee (CAC; FAO/WHO, 2009; Farah, 2009; Ghosh; Venkatachalapath, 2014).

\subsubsection{Wet processing}

The wet processing is more sophisticated and used to generate a better-quality beverage. There are many different versions of this method where only ripe cherries are used. They c an be selectively picked and separated mechanically or in flotation tanks. Sorting is followed by mechanical de-pulping, soaking, and fermentation in a tank usually for 12-36 hours.

Fermentation may occur naturally or with the addition of microorganisms or enzymes and is employed to remove the remaining pulp and silver skin. During fermentation acidity increases and $\mathrm{pH}$ may decrease to 4.5 . The naked beans (parchment coffee) are then extensively washed in clean water tanks or in specific washing machines. Then the beans are dried in yards or on suspended in ventilated tables, combined with hot air drying. After drying, the remaining part of the hull often is mechanically removed (dehulled) after washing. Wet processing frequently is used in places where coffee is harvested by manual picking, such as Colombia, Asia, and Central America. Due to higher market value, various farms in countries producing larger volumes, such as Brazil, also have adopted it. (Bee et al., 2005; CAC; FAO/WHO, 2009; Farah, 2009; Knopp et al., 2006).

\subsection{Dry Processing Versus Wet Processing}

The major difference between dry and wet processing is that in wet processing most of the outer parts of seeds is re moved before drying, in addition to the silver skin, which is removed during and after the fermentation process. A l t e r natively, a method called semi-dry or semi-washed method, which is a combination of both dry and wet methods. It has been developed in Brazil. The method consists of 
washing and selecting the seeds in flotation tanks and depulping as in the wet process, except the fermentation step is excluded (CAC; FAO/WHO, 2009; Farah, 2009) Coffee seeds treated by the dry and semi-dry processes, maintaining the polysaccharide-rich silver skin, often are used in espresso coffee blends because they tend to add more body and sweetness to the beverage than the wet pro-cessed seeds (Farah, 2009).

Although coffee beans are fairly of uniform size and proportion, they are graded first by size and then density by running the beans through sieves and screens with specialized holes (Knopp et al., 2006).

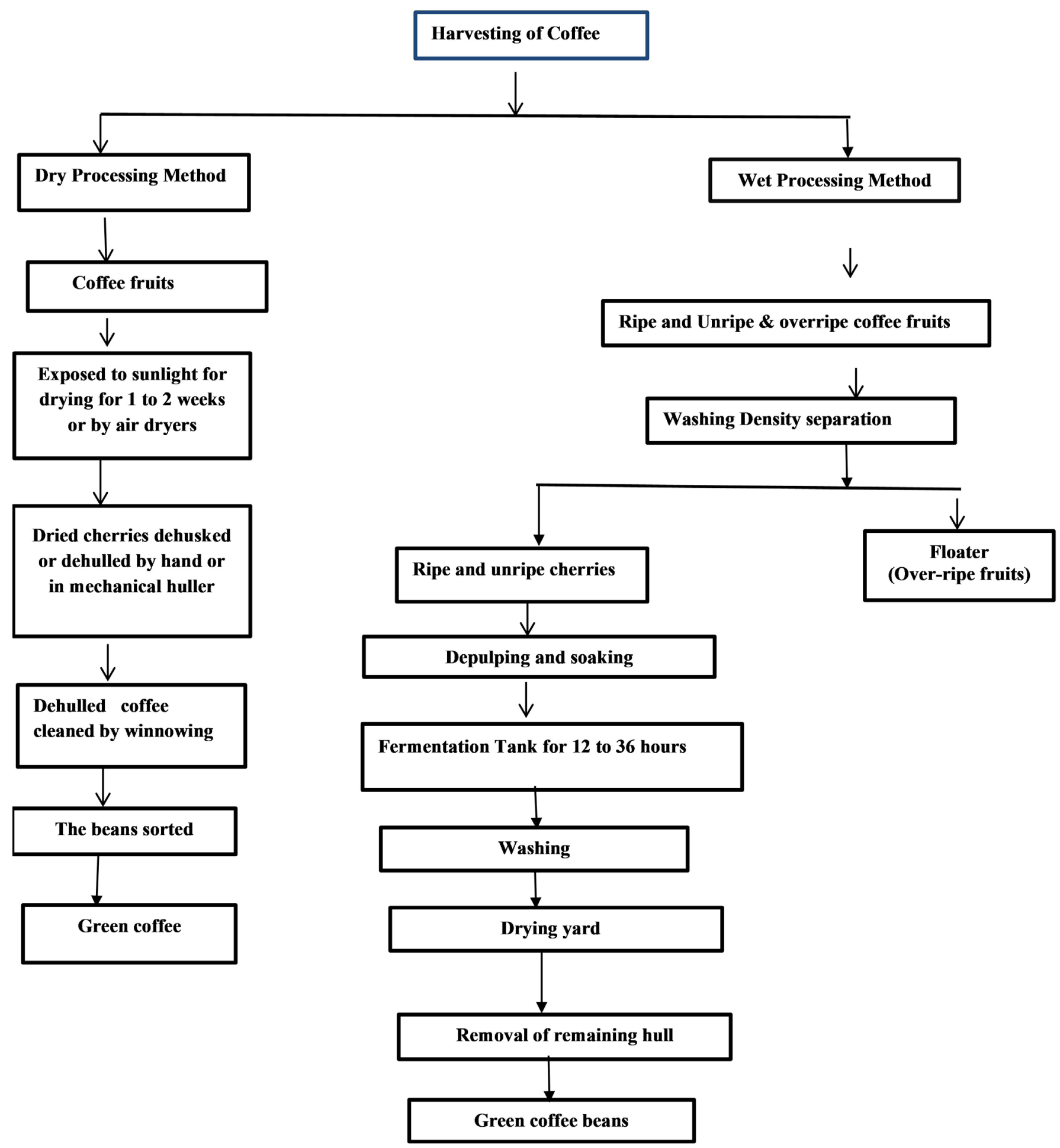

Figure 3: Flow Diagram of Coffee Processing Method. 
After the beans are treated by either method, they are stored or mechanically, manually, and/or electronically sized and sorted to separate and count defective beans. This process may be followed by an additional sorting with ultraviolet excitation to separate defects that may be produced during both dry and wet processing (Farah, Santos, 2015).

\subsection{Storage}

Before coffee beans are shipped, however, they have to be stored, and to prevent them spoiling or losing quality, a number of precautions have to be taken. These include paying particular attention to humidity, storage facility location, and storage duration (Knopp et al., 2006).

After marketing, green coffee beans are ready to undergo roasting. They may also be decaffeinated, steamtreated, or stored before roasting.

\subsection{Roasting of coffee Beans}

Green coffee is devoid of the pleasant aroma and flavour that are appreciated worldwide in roasted coffee. The desired aroma and flavour of coffee beans used for beverage preparation are developed during the roasting process, where the beans undergo a series of reactions leading to the desired changes in the chemical and physical composition (Hicks, 2002). So, to obtain a good quality cup of coffee with specific organoleptic properties (flavour, aroma, and colour), the roasting of coffee beans is very important (Dutra et al., 2001) The characteristic flavour and aroma of coffee result from a combination of hundreds of chemical compounds produced by the reactions that occur during the roasting (Hernandez et al., 2007). This implies controlling the roasting time and temperature so that they are optimum for the required chemical reactions to occur, without burning of beans and compromising the flavour of the final beverage. In general, in conventional roasting process the temperature is in the range from 200 to $230^{\circ} \mathrm{C}$, and the process time is ranging from 12 to 20 minutes. However, these values can vary greatly, depending on the degree of roast required (light, medium or dark), on the type of roaster used, and also on the variety, age, moisture content, etc. of the coffee beans (Mendes et al., 2001). The roasting process can be divided into three consecutive stages: drying, roasting or pyrolysis and cooling (Hernandez et al., 2007).

Physical changes in coffee that occur roasting include reduction in mass due to loss of moisture and decomposition of carbohydrates, increase in volume of coffee beans, lowering of density as a result of puffing and increase in brittleness (Mwithiga; Jindal, 2003; Noor-Aliah et al., 2015).

During roasting, coffee beans lose their strength and toughness there by become brittle and fragile (Pittia; Nicoli; Sacchetti, 2007).

Physical parameters such as weight loss, volume change, and density are used to control the coffee bean roasting quality (Schenker et al., 2002; Pittia; Dalla Rosa; Lerici, 2001; Alessandrini et al., 2008).

The degree of roasting is determined by total weight loss of green coffee beans after roasting (Jokanovića et al., 2012) which also measure sthe efficiency of green bean preparation.

The changes in bulk density are implied in bean expansion and in the formation of a characteristic porous structure of the roasted coffee bean (Pittia; Dalla Rosa; Lerici, 2001).

R o a sted coffee at higher temperatures shows greater volumetric expansion and has larger pores, facilitating oil migration and oxidation during storage (Schenker et al., 2002) contributing decrease the quality of beverage. Around $15 \%$ of grain is related to dry matter content and higher values of th is property reflect in better quality grains. The expansion $\mathrm{m}$ e $\mathrm{c}$ hanism can be studied as a balanced process between the formation of gas (water vapor and $\mathrm{CO} 2$ ) as the driving force, and the state transitions of the cell wall material as the res istance force. The colour changes from green to brown through the carmelization of the sugar and other carbohydrates and the formation of certain pigmented substances produced by chemical reactions known as Strecker's reactions. These colour changes occur only at the highest temperature, so the higher the temperature the darker the coffee (Franca et al., 2005).

The main chemical changes however concern the presence of some groups of substances that vary before and after roasting and the formation of new compounds. The explosion of a limited number of cells causes rather popping sounds when the coffee is thus said to be "squeaking". When the cell wall splits through too much pressure, gas is released as well as volatile aromas; this explains why, when increasing of the final temperature of the roast, up to a certain point, the aroma will increase and then diminish. Not only does the aroma vary in accordance with the temperature but also the corresponding degrees of bitter and acid taste: bitterness increases with the temperature whereas acidity diminishes. The most delicate stage in the roasting process is the final stage: above $200{ }^{\circ} \mathrm{C}$ the chemical reactions, hitherto endothermic (heat absorbing) become exothermic (heat producing). The increase in temperature of the coffee therefore becomes more rapid (Franca et al., 2005).

Roasting of coffee beans leads to a net loss of matter in the forms of $\mathrm{CO}_{2}$, water vapor, and volatile compounds. During roasting degradation of polysaccharides, sugars, amino acids, and chlorogenic acids occurred, resulting in the formation of caramelization and condensation products (Diaferia, 2019). An increase in organic acids and lipids was found, while there is no change in caffeine and trigonelline (N-methyl nicotinic acid) contents (Buffo; Cardelli-Freire, 2004). The principal organic acids present in green beans include citric, malic, chlorogenic, and quinic acids. During roasting process, the levels of first three acids decrease, but quinic acid increases because of the degradation of chlorogenic acids (Ginz et al., 2000). Formic and 
acetic acids levels increase with the medium roasting degree and then begin to fall as roasting is continued. According to Balzer (Balzer, 2001), a rapid increase in titratable acidity during roasting was observed from green to medium roast, followed by a smaller decrease as roasting proceeded.

The chemical reaction products formation are highly dependent on the roasting time-temperature profile applied. Excessive roasting produces more bitter coffee without satisfactory aroma, whereas very short roasting time may found insufficient to develop full organoleptic characteristics (Yeretzian et al., 2002; Lyman et al., 2003; Buffo; CardelliFreire, 2004). Though, most of the phenolic antioxidants naturally occurring in coffee bean are lost during roasting, the formation of other antioxidants from Maillard reactions during roasting can enhance the antioxidant activity of coffee. As compared to medium roasted coffee, dark roasted coffee exhibited lower radical scavenging activity than medium roasted coffee due to the degradation of polyphenol. Hence, the antioxidant activity will also depend on roasting severity and type of coffee (Giampiero Sacchetti, Paola; Dino, 2009).

Speciality coffees are generally roasted in small batches, either by drum roasting or hot-air roasting commonly. Drumtype roasting machines roast the coffee beans as they tumble in a rotating drum that is typically heated by gas or wood. When the desired roast is achieved, the beans are poured into a cooling hopper to prevent them from overcooking. A traditional drum roasting machine consists of three main parts: a heat generator, a vessel (where coffee is continuously agitated by rotation of the vessel or by forced heated air), and a cooler (where the coffee temperature is reduced) (Knopp et al., 2006).

The hot-air roaster, also known as a fluid bed roaster, roasts the coffee beans as they lift and tumble on a current of hot air. Most green coffee is roasted at approximately $400{ }^{\circ} \mathrm{C}$. The roasting process causes the coffee beans to swell and increase in size by over $50 \%$, while at the same time greatly reducing their weight. Once the beans are kept out of the roasting machines they must be cooled immediately to prevent autocombustion from modifying the proper grade of toasting that has been achieved. There are three ways of cooling roasted beans: i) Water cooling: a shower of water chills the hot roasted beans. Coffee absorbs water so this process increases the specific weight, ii) Cooling in normal air, iii) Cooling in forced air (Knopp et al., 2006).

Grinding of roasted coffee beans is the last operation of coffee processing. Coffee was used to grind in wooden or marble mortars with a pestle in the early days. But in modern times, coffee beans are grinded by electrical grinder (Knopp et al., 2006).

\section{CONCLUSIONS}

Coffee is one of the most popular beverages around the world. Harvesting and postharvest methods that are used for production of coffee beans have vital roles in coffee beverage quality and on health benefits. The major steps of Coffee processing include dry and wet methods to prepare green coffee, then grading and sorting, and roasting. Roasting is probably the most important step of coffee processing responsible for development of favourable flavour and aroma making coffee enjoyable.

\section{ACKNOWLEGEMENTS}

The author is grateful to Mrs. Suparna Bag, Proprietor, Binidini Matri Seva Sadan, Mahishadal, Purba Medinipur, WB, India, for providing original photographs of coffee.

\section{REFERENCES}

ALESSANDRINI, L. et al. Near infrared spectroscopy: An analytical tool to predict coffee roasting degree. Analytica Chimica Acta, 625(1):95-102, 2008.

ANTHONY, F. et al. The origin of cultivated Coffea arabica L. varieties revealed by AFLP and SSR markers. Theoretical and Applied Genetics, 104:94-900, 2002.

BEE, S. et al. The raw bean. In: VIANNI, R.; ILLY, A. Espresso coffee: The science of quality. 2nd ed. London: Elsevier Academic Press. p. 87-178, 2005.

BUFFO, R. A.; CARDELLI-FREIRE, C. Coffee flavour: An overview. Flavour and Fragrance Journal, 19(2):99104, 2004.

CAGUE, R. et al. Beyond the bean: Redefining coffee quality. Environment and Natural Resource Management and Agribusiness Practice Networks, p.1-18, 2009.

CHARRIER, A.; BERTHAUD, J. Coffee botany, biochemistry and production of beans and beverage. In: CLIFFORD, M. N.; WILLSON, K. C. Botanical classification of coffee. Connecticut, USA: The AVI Publishing Company, p. 13-47, 1987.

CODEX ALIMENTARIUS COMMISSION - CAC, Joint FAO/WHO FOOD STANDARDS PROGRAMME. Report of the 3rd session of the codex committee on contaminants in foods, proposed draft code of practice for the prevention and reduction of ochratoxin a Contamination in Coffee, Appendix VI, pp 73. Agenda Item 8. ALINORM 09/32/41, 2009.

DAVIS, A. P. et al. An annotated taxonomic conspectus of the genus Coffea (Rubiaceae). Botanical Journal of the Linnean Society, 152(4):465-512, 2006. 
DAVIS, A. P. Searching for the relatives of Coffea (rubiaceae, ixoroideae): The circumscription and phylogeny of Coffeeae based on plastid sequence data and morphology. American Journal of Botany, 94(3):313-29, 2007.

DIAFERIA F. Physical properties of coffee related to the roasting process. p.1-59, 2019.

DUTRA, E. R. et al. A preliminary study on the feasibility of using the composition of coffee roasting exhaust gas for the determination of the degree of roast. Journal of Food Engineering, 47(3):241-246, 2001.

FARAH, A. et al. Correlation between the chemical attributes of coffee and cup quality. Food Chemistry, 98:373-380, 2006.

FARAH, A. Coffee as a speciality and functional beverage. In: PAQUIN, P. Functional and speciality beverage technology. 1st ed. Cambridge: Woodhead Publishing in Food Science, Technology and Nutrition, p.370-395, 2009.

FARAH, A.; SANTOS, T. F. D. The coffee plant and beans: An introduction. In: PREEDY, V. R. Coffee in health and disease. London: Academic Press, p.5-10, 2015.

FRANCA, A. S. et al. Composition of green and roasted coffees of different cup qualities. LWT, 38(7):709-715, 2005.

GIAMPIERO SACCHETTI, C. D. M.; PAOLA, P.; DINO.; $M$. Effect of roasting degree, equivalent thermal effect and coffee type on the radical scavenging activity of coffee brews and their phenolic fraction. Journal of Food Engineering, 90(1):74-80, 2009.

GINZ, M. et al. Formation of aliphatic acids by carbohydrate degradation during roasting of coffee. European Food Research and Technology, 211(6):404-410, 2000.

GHOSH, P.; VENKATACHALAPATH, N. Processing and drying of Coffee - A review. International Journal of Engineering Research \& Technology, 3(12):21-31, 2014.

HERNANDEZ, J. A. et al. Analysis of the heat and mass transfer during coffee batch roasting. Journal of Food Engineering, 78(4):1141-1148, 2007.

HICKS, P. A. Postharvest processing and quality assurance for specialty/organic coffee products. FAO Regional Office for Asia and the Pacific, Bangkok, Thailand. 2002.

JOKANOVIĆA, M. R. Changes of physical properties of coffee beans during roasting. APTEFF, 43:1-342, 2012.

KNOPP, S. Influence of processing on the content of sugars in green Arabica coffee beans. European Food Research Technolology, 223:95-201, 2006.
LASHERMES, P. Molecular characterisation and origin of the Coffea arabica L. genome. Molecular Genetics and Genetics, 261:259-66, 1999.

LYMAN, D. J. FTIR-ATR Analysis of brewed coffee: Effect of roasting conditions. Journal of Agricultural and Food Chemistry, 51(11):3268-3272, 2003.

MENDES, C. L. et al. Optimization of the roasting of robusta coffee (C. canephora conillon) using acceptability tests and RSM. Food Quality and Preference, 12(2):153-162, 2001.

MINAMISAWA, M. et al. Determination of biologically active substances in roasted coffee using a diode-array HPLC system. Analytical Sciences, 20(2):325-328, 2004.

MURTHY, P. S.; NAIDU, M. M. Sustainable management of coffee industry by-products and value addition - A review. Resources, Conservation and Recycling, 66:45-58, 2012.

MWITHIGA, G.; JINDAL, V. K. Physical changes during coffee roasting in rotary conduction-type heating units. Journal of Food Process Engineering, 26(3):543-558, 2003.

NOOR-ALIAH, A. M. et al. A review of quality coffee roasting degree evaluation. Journal of Applied Science and Agriculture, 10(7):18-23, 2015.

PITTIA, P.; DALLA ROSA, M.; LERICI, C. R. Textural changes of coffee beans as affected by roasting conditions. Lebensmittel-Wissenshaft und Technologie, 34(3):168-171, 2001.

PITTIA, P.; NICOLI, M. C.; SACCHETTI, G. Erratum: Effect of moisture and water activity on textural properties of raw and roasted coffee beans. Journal of Texture Studies, 38(1):116-134, 2007.

SCHENKER, S. et al. Impact of Roasting Conditions on the Formation of Aroma Compounds in Coffee Beans. Journal of Food Science, 67:60-66, 2002.

TOCI, A.T.; FARAH, A. Volatile compounds as potential defective coffee beans' markers. Food Chemistry, 108(3):1133-1141, 2008.

UKERS, W. H. All about coffee. New York: The Tea and Coffee Trade Journal Company, 1922. 796p.

WINSTON, E. et al. Arabica coffee manual for Lao-PDR. 2005. Available in: http://www.fao.org/docrep/008/ ae939e/ae939e00.htm. Access in: February 07, 2022.

YERETZIAN, C. et al. From the green bean to the cup of coffee: Investigating coffee roasting by on-line monitoring of volatiles. European Food Research and Technology 214(2):92-104, 2002. 